\title{
Testing Estimates of Housing Cost Differences among US Metropolitan Areas
}

\author{
Todd Easton \\ Robert B. Pamplin, Jr. School of Business Administration, University of Portland, 5000 N. Willamette Boulevard, \\ Portland, OR 97203, USA \\ Correspondence should be addressed to Todd Easton; easton@up.edu
}

Received 11 June 2014; Revised 16 October 2014; Accepted 23 October 2014

Academic Editor: Eric Koomen

Copyright (C) 2015 Todd Easton. This is an open access article distributed under the Creative Commons Attribution License, which permits unrestricted use, distribution, and reproduction in any medium, provided the original work is properly cited.

\begin{abstract}
This paper investigates the accuracy of six measures of housing cost differences among US metropolitan areas. Using Census data from 177 metropolitan areas, it tests the measures in two ways. First, it tests the ability of changes in the measures to predict changes in the shelter component of the metropolitan CPI from 1990 to 2000. Second, it tests the ability of the measures themselves to predict a proxy in 2000. A measure based on Fair Market Rents calculated by HUD placed second on the first test but did badly on the second. The housing component of the ACCRA index, a living cost measure frequently used by researchers, performed poorly on both tests. The top performer on both tests was a measure based on the average rent per room for a metropolitan area's dwellings. Researchers wishing to control for living cost differences among places should consider including it in their living cost index.
\end{abstract}

\section{Introduction}

Researchers would like to investigate real earnings differences among urban areas in the US, but there is no good, official measure of living cost differences among places ${ }^{1}$. For example, the Consumer Price Index (CPI) measures changes in costs over time in a place, not differences in costs among places. Researchers have responded to this problem with a variety of strategies. The most frequent of these is to use the ACCRA Cost of Living Index, an index compiled by a nonprofit organization. The suitability of this response is uncertain. While the ACCRA Index is available for a large set of metropolitan areas, data to calculate it are collected by volunteers and its accuracy has seldom been compared to practical alternatives.

This research contributes to a solution to this problem, in two ways. First, it evaluates alternative measures of housing cost differences among US metropolitan areas. ${ }^{2}$ That evaluation is central to deciding how to best measure living costs, because the cost of housing is, by far, the largest source of variation in living costs among metropolitan areas. ${ }^{3}$ Second, because the housing cost portion of the ACCRA Index is one of the measures it evaluates, this research offers evidence regarding the wisdom of using the full ACCRA Index as a measure of living cost differences.

This study evaluates six housing cost measures against two benchmarks. Initially, I test the ability of changes in each of the measures to predict changes in the shelter portion of the metropolitan CPI in 25 large metropolitan areas. Then, I test the ability of each measure to predict a proxy for a metropolitan area's housing costs: the average size of its dwellings. Using this proxy allows me to test performance of housing cost measures in 176 metropolitan areas.

This research builds on a prior paper by Easton, one which evaluated the same six measures of housing cost differences [1]. He tested them against a different benchmark: a housing cost index taken from work by Aten [2]. She created an experimental measure of living costs in 26 large metropolitan areas, using Bureau of Labor Statistics (BLS) data collected to calculate the CPI. By utilizing two new benchmarks and, in one test, a much larger set of metropolitan areas, this research provides additional evidence regarding the best way to measure housing cost differences among areas.

In addition to Easton's paper, two other articles provide some evaluation of metropolitan living cost measures. Koo et al. create an index to measure metropolitan price levels 
between July 1988 and June 1989 [3]. They estimate price levels in 22 CPI metropolitan areas using BLS data and calculate a mean absolute difference of $7.8 \%$ between their new index and the ACCRA Index; they conclude the ACCRA Index has substantial errors, errors that result mostly from sampling and aggregation bias. Curran et al. provide a theoretical overview of alternative cost of living measures, concentrating on those calculated by the Council for Community and Economic Research (also known as C2ER), the National Research Council (NRC), and the Economic Research Institute [4]. They conclude C2ER's measure, the ACCRA Index, is best, because it includes prices of a broad set of goods (not just housing) and carefully specifies the goods to be priced. They fault NRC's measure for ignoring nonhousing prices and for using a biased measure of housing costs (Fair Market Rents calculated by the Department of Housing and Urban Development). They fault the Economic Research Institute's measure for inconsistencies in the goods priced and for implausible component weights for low income families.

Between 1991 and 2008, at least six articles relied solely on the ACCRA Index to measure living costs: Browne and Trieschmann's study of the compensation of full professors at research universities [5], Cutler and Glaeser's examination of residential segregation's impact on real earnings differentials between African American workers and other workers [6], Gisser and Dávila's analysis of earnings differences between unskilled farm workers and unskilled urban workers [7], Olson et al.s study of the influence of local wage levels and living costs on pay for federal government jobs [8], Easton's study of immigration's impact on the wages of native workers [9], and Glaeser and Tobio's examination of the influence of climate and Southern location on real wage income [10]. Not one of these papers included an evaluation of the ACCRA Index's accuracy or an examination of the sensitivity of results to measuring living costs using alternative methods.

Three papers improve on those mentioned above by using multiple measures of living costs. Dumond et al. study metropolitan variation in living costs, amenities, and wages [11]. They argue that estimates of real wages should rely on partial adjustment, that is, on models that only include living cost measures as independent variables. They estimate a log living costs coefficient of .526 in a model predicting $1989 \mathrm{log}$ wages with controls for amenities. When they replace the ACCRA Index living cost measure with an index they create from the BLS comparative cost index, the coefficient falls to .366 . ${ }^{4}$ Winters' 2009 article also predicts nominal wages at the metropolitan level [12]. With the ACCRA Index, he calculates a $\log$ living cost coefficient of .314, a value which rises to .760 when he replaces the ACCRA Index with his rent-based index. He calculates the rent-based index by replacing the housing cost portion of the ACCRA Index with a hedonic measure of rents for tenant-occupied dwellings. ${ }^{5}$ The rentbased index is a weighted average of the hedonic measure and the nonhousing cost portion of the ACCRA Index. Moretti studies the earnings advantage of high-education workers, by comparing the earnings of workers with a college degree or more to the earnings of workers with only a high school degree [13]. For example, he calculates that the nominal earnings advantage of the first group was $60 \log$ points in 2000.
He then constructs five living cost indexes to calculate real wages at the metropolitan level. One index measures housing costs with the average rent of 2- and 3-bedroom apartments and nonhousing costs with the ACCRA Index. Using it, the real earnings advantage is $54 \log$ points in 2000. Another index measures housing costs with the average rent of 2and 3-bedroom apartments and imputes nonhousing costs using the relationship between housing and nonhousing costs in CPI data. Using that index, the real earnings advantage is $51 \log$ points in 2000 .

\section{Six Measures of Housing Costs}

This section presents the six housing cost measures tested. ${ }^{6}$ Measure A, Measure B, and Measure C embody hedonic approaches to valuing housing services and require extensive calculations using Census data. Measure D also uses Census data, but only for a simple calculation. Measure E and Measure $\mathrm{F}$ are similarly straightforward but use different datasets. Measure E is calculated directly from HUD Fair Market Rents and Measure F is calculated directly from the ACCRA Index.

Measure A estimates rents on tenant-occupied units in each metropolitan area. By ignoring owner-occupied dwellings, it implicitly assumes that rents and owners' equivalent rents move in tandem. The approach is analogous to the one the CPI uses to value housing services. ${ }^{7}$ I estimate the following relationship in each metropolitan area in the sample:

$$
\ln \left(\text { Rent }_{i}\right)=\alpha_{0}+\beta X_{i}+\varepsilon_{i},
$$

where Rent is the rent, net of utilities, for the $i$ th housing unit in the metropolitan area's sample; $\beta$ is a vector of attribute rents, with one element for each dwelling attribute; $X_{i}$ is a vector of the dwelling attributes; and $\varepsilon$ is a random disturbance term. ${ }^{8}$

Once attribute rents have been estimated, I use them to predict the average tenant-occupied unit's rent in each metropolitan area and then calculate the housing cost index by dividing each metropolitan area's predicted rent by the average predicted rent in all metropolitan areas. ${ }^{9}$

Measure B uses both rented and owner-occupied units to estimate housing costs. Within each metropolitan area, it estimates a dwelling's cost, which is either what the household pays in rent or the value of the dwelling:

$$
\ln \left({\text { Dw } \operatorname{Cost}_{i}}_{i}\right)=\alpha_{0}+\alpha_{1} \text { OwnerOcc }_{i}+\beta X_{i}+\varepsilon_{i},
$$

where DwCost $t_{i}$ is the $i$ th dwelling's "cost" (the monthly rent, net of utilities, if the unit is rented, or the market value, if the unit is owner-occupied) and Owner Occ is a dummy variable identifying whether the $i$ th unit is an owner-occupied dwelling. ${ }^{10}$

This approach, developed by Crone et al. [14], assumes the attributes of a rented dwelling affect its rent by the same proportion as the attributes of an owner-occupied dwelling affect its market value. While this assumption is restrictive, it allows owner-occupied housing to directly influence estimated attribute rents. Once attribute rents are estimated, the 
Measure B housing cost index is calculated with them in the same manner as the Measure A index. ${ }^{11}$

Measure $\mathrm{C}$ is like Measure $\mathrm{B}$, in the fact that it includes both rented and owned units, but it pools all metropolitan areas to estimate

$$
\ln \left(\text { DwCost }_{i j}\right)=\alpha_{1} \operatorname{OwnerOcc}_{i j}+\beta X_{i j}+\gamma M_{j}+\varepsilon_{i},
$$

where $D w$ Cost $_{i j}$ is the cost for dwelling $i$ in metropolitan area $j ; \gamma$ is a vector of $j$ coefficients, one for each metropolitan area; and $M_{j}$ is a vector of $j$ dummy variables, one for each metropolitan area in the sample.

Two aspects of this relationship should be noted. First, since it is estimated for all metropolitan areas simultaneously, rather than for each one individually, it is much easier to estimate than (1) or (2). Second, since it constrains $\alpha_{1}$ to be the same across metropolitan areas, it will improve estimates of owner's equivalent rents if speculation pushes house values above what fundamentals warrant in some areas.

Measure $\mathrm{C}$ housing cost index is calculated from the coefficients estimated for the dummy variables in vector $M$. The antilog of each coefficient is taken, to get an estimate of each metropolitan area's average rent. Then, each area's average is divided by the across-metropolitan area average rent.

As mentioned above, the fourth, fifth, and sixth housing cost measures require little calculation. The fourth and fifth are based on tenant-occupied dwellings, while the sixth is based mostly on owner-occupied housing. To calculate the fourth, Measure D, I calculate the average rent per room for each metropolitan area and then create the housing cost index by dividing those averages by the mean of all the metropolitan averages. Rather than relying on Census data, Measure E uses Fair Market Rents (FMRs) calculated by the Department of Housing and Urban Development (HUD). A metropolitan area's FMR generally estimates the 40th percentile of the rent distribution for tenant-occupied units three years or older. ${ }^{12}$ To calculate the housing cost index for Measure E, each metropolitan area's FMR for two-bedroom apartments is divided by the mean of the two-bedroom FMRs for all metropolitan areas in the sample. Measure F is simply the ACCRA Index's housing component divided by 100 , so that its scaling matches that of the other measures. Dwellings selected for C2ER's sample are meant to be typical of those lived in by managers and professionals in the top quintile of the income distribution. C2ER calculates the housing component using a weighted average of the average monthly mortgage payment on a new 2,400-square-foot home and the average rent for a two-bedroom apartment. The weights are based on Consumer Expenditure Survey results for top quintile households. For example, in 2012 the weights were about $82 \%$ and $18 \%$, respectively. ${ }^{13}$

\section{Data}

There are four sources for the data used in the study. Data to calculate most of the housing cost measures and the housing cost proxy come from the 5\% Public Use Microdata Set (PUMS) of the 1990 and 2000 Censuses [15]. Additional data to compute housing cost measures come from Fair Market Rents calculated by HUD. ${ }^{14}$ C2ER, also known as the Council for Community and Economic Research, provided the ACCRA Index and its components; the variable used here is the housing cost component. The metropolitan CPI comes from the BLS.

I use Census data for 177 metropolitan areas, the ones that had a population greater than 200,000 in both 1990 and 2000 . For metropolitan areas with populations under 400,000, all the PUMS records are included. However, sampling rates are reduced as metropolitan populations grow, to keep dataset sizes manageable. For example, for areas with populations over 2 million, the sampling rate is $10 \%$. The dataset includes 580,000 dwellings in 1990 and 730,000 in 2000.

\section{Methodology}

The six housing cost measures described above are plausible measures of differences in the level rents and owner's equivalent rents among metropolitan areas. Two tests evaluate their accuracy.

4.1. Test One. The first test is based on a simple idea: even though the housing cost measures gauge price differences among places, not changes over time, a good housing cost measure should accurately track changes in price. If it does not, a measure that is accurate in one year will not be accurate subsequently. Since the shelter portion of the metropolitan CPI should accurately track changes in housing costs in major metropolitan areas, I test the accuracy of each of the six measures by seeing how well it predicts changes in the metropolitan CPI by estimating

$$
\text { ChCPISh }_{i}=\alpha+\beta \text { ChHCMeasure }_{i}+\varepsilon_{i},
$$

where $\mathrm{ChCPISh}_{i}$ is the change in the shelter portion of the CPI in metropolitan area $i$, from 1990 to 2000, and ChHCMeasure $_{i}$ is the change in a particular housing cost measure (e.g., Measure A) in metropolitan area $i$, from 1990 to $2000 .^{15}$

After predicting the change in the shelter CPI with each housing cost measure, I use $R$-squared to compare the accuracy of the predictions. ${ }^{16}$

4.2. Test Two. The second test compares the ability of the housing cost measures to predict a proxy: the average size of a metropolitan area's dwellings. The justification of the proxy is this: changes in the opportunity cost of space should change the amount of space households consume. Since the Census lacks more precise measures, I use the number of rooms in a dwelling to measure its size. The second test estimates

$$
\text { Rooms }_{i}=\alpha+\beta \text { HCMeasure }_{i}+\gamma X_{i}+\varepsilon_{i},
$$

where Rooms is the average number of rooms per dwelling, across all households in metropolitan area $i$; HCMeasure is the value of a particular housing cost measure for metropoli$\tan$ area $i ; X$ is a vector of six controls for metropolitan area $i$ : average household size, average household income, and the 
proportions of the population that are black, Hispanic, Asian, and recent immigrants; and $\varepsilon$ is a random disturbance term.

Controls are included to evaluate the unique information each housing cost measure contains. Rises in household size are expected to increase the number of rooms a household dwells in, by increasing its demand for space. Space is expected to be a normal good, so that rises in household income are associated with rises in the number of rooms a household occupies. Measures of metropolitan ethnicity control for differences in taste and wealth among ethnic groups. The proportion of the population that is recent immigrants also controls for differences in taste and wealth, but this time between immigrants who arrived recently and others.

I implement the second accuracy test in two ways. First, I gauge the marginal contribution made by each of the six measures of housing costs, by predicting the proxy with just the controls and then adding each measure in turn. Second, I gauge the total contribution by predicting the proxy with each housing cost measure alone. In combination, the rise in $R$-squared in the first exercise and the actual $R$-squared in the second exercise provide a minimum and a maximum magnitude for each measure's contribution to explaining the variation in the proxy.

\section{Results}

This section presents the results of the two accuracy tests described above. It first presents the results of estimating (4), the equation predicting the change in an area's metropolitan $\mathrm{CPI}$, using the first five housing cost measures (Measure F cannot be included, since C2ER recenters its index annually). Then, it presents the results of using all six measurements to estimate (5), the equation predicting the proxy.

5.1. Test One. Shelter CPI changes are predicted for 25 large metropolitan areas for which the BLS calculated metropolitan CPIs in 1990 and 2000. Table 1 reports the results. Table 2 reports means and standard deviations for variables in Table 1, as well as for each variable appearing in subsequent tables. Comparing the $R$-squared values in Table 1 , Measure D (based on average rent per room) is, by a substantial margin, the best predictor of the change in the shelter CPI. The 1990 to 2000 change in Measure D predicts $69 \%$ of the variation in the CPI change. Measure E (based on Fair Market Rents) is second best and Measure $\mathrm{C}$ (the pooled hedonic measure of tenant and owners' equivalent rents) is third best.

Figure 1 records the predictive accuracy of the measures in each metropolitan area. One notable feature of the figure is the consistent performance of the average rent per room measure. It is the only housing cost measure whose squared residual is less than .006 for every metropolitan area. In contrast, Measure E's squared residual is above .006 for Honolulu and far above .006 for Denver-Boulder-Greeley.

The residuals for Measures D and E are well behaved. The relationship between the independent and dependent variable is linear. The distribution of the residuals is close to normal and homoscedastic.

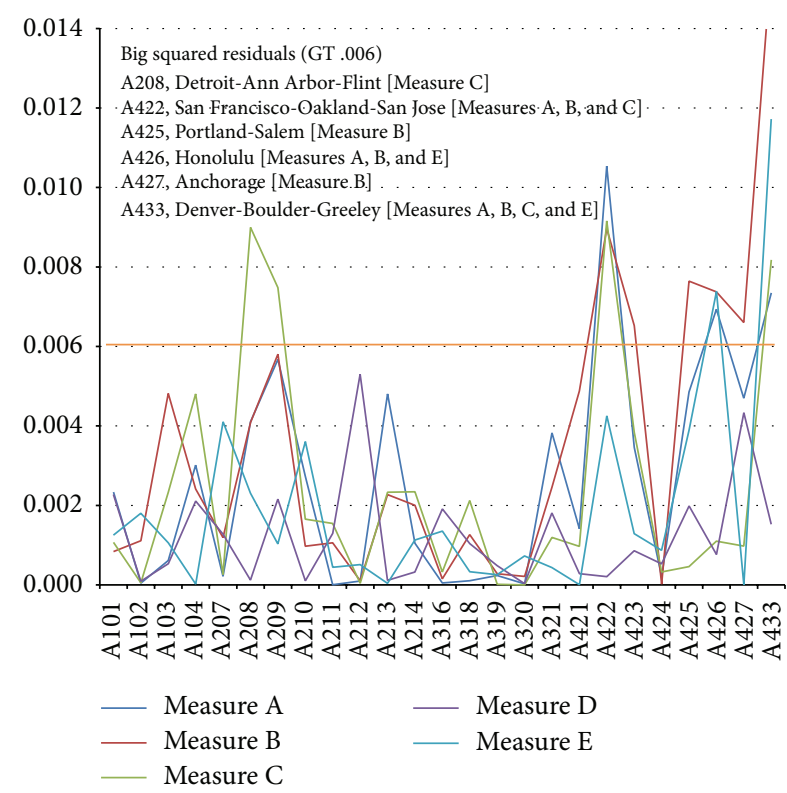

FIGURE 1: Squared residuals for Table 1 regressions.

5.2. Test Two. Values of the proxy are predicted in the full sample of 177 metropolitan areas using Measure A through Measure E. After that, the proxy is predicted using all housing cost measures, for a smaller group of 87 metropolitan areas for which Measure F can be calculated. There are two sets of predictions: the first includes all households in the sample, while the second includes a subsample, households that moved into their dwelling in the last five years, a group I label "recent movers." All the predictions use data from the 2000 Census.

5.2.1. All Households. Tables 3 and 4 show predictions of the proxy for all households using the full set of controls. Table 3 predictions are for the full sample, while Table 4 predictions are for the 87 areas for which the sixth housing cost measure, the one based on the ACCRA Index, is available in 2000.

Based on these estimations, (5) seems a plausible model of average dwelling size. Examining the control variables, one can see that the average number of rooms in a metropolitan area's dwellings rises by between .019 and .040 for each $\$ 1,000$ rise in household income, holding other household characteristics constant. The average number of rooms rises between .40 and .61 for each additional household member. A rise in the proportion of residents who are black, Asian, or Hispanic is consistently associated with a reduction in the average number of rooms. The same is true for a rise in the proportion of the population that is recent immigrants. With the exception of the coefficients associated with the proportion black variable in Table 4, each coefficient presented is statistically significant.

Turning our attention to the housing cost measures, what do the tables say about their ability to predict the average dwelling size in a metropolitan area? First consider the fullsample regressions in Table 3 . The $R$-squared values there suggest that Measure $C$ (the pooled hedonic estimator) is 
TABLE 1: Predicting the 1990 to 2000 change in the shelter portion of the CPI. ${ }^{\dagger}$

\begin{tabular}{lllllllr}
\hline Housing cost measure & \multicolumn{2}{c}{ Constant } & \multicolumn{2}{c}{ Slope } & $R^{2}$ & SEE & Areas in sample \\
\hline A & $0.203^{*}$ & $(0.040)$ & $0.438^{*}$ & $(0.129)$ & 0.333 & 0.0545 & 25 \\
B & $0.254^{*}$ & $(0.044)$ & 0.233 & $(0.123)$ & 0.135 & 0.0621 & 25 \\
C & $0.227^{*}$ & $(0.030)$ & $0.294^{*}$ & $(0.076)$ & 0.395 & 0.0520 & 25 \\
D & $0.104^{*}$ & $(0.033)$ & $0.546^{*}$ & $(0.076)$ & 0.693 & 0.0370 & 25 \\
E & $0.184^{*}$ & $(0.032)$ & $0.525^{*}$ & $(0.106)$ & 0.514 & 0.0466 & 25 \\
\hline
\end{tabular}

${ }^{\dagger}$ In this and subsequent tables, an asterisk following a coefficient indicates that it has a $p$-value less than .05 in a two-tail test.

the best measure, with Measure D (based on rent per room) placing second and Measure B (the metro-by-metro hedonic estimator of rents and owner's equivalent rents) placing third. Measure C raises $R$-squared .080 relative to the regression with just controls, while Measure D raises it by .057. The other measures contribute substantially less explanatory power. The coefficient of Measure C says that, ceteris paribus, a 10percentage-point rise in housing cost is associated with a .069 room decline in the average dwelling's size.

Now consider the ACCRA sample regressions in Table 4. How do the results there compare with those in Table 3? The top three performers are the same, but the identities of the first place finisher and second place finisher are reversed. Moreover, the marginal contribution of each measure is smaller, with Measure A (the metro-by-metro hedonic estimator of tenant rents), Measure E (the estimator based on Fair Market Rents), and Measure F (the estimator based on the ACCRA Index) contributing practically nothing.

Overall, the all-households regressions including controls suggest that Measure D and Measure $C$ are the best gauges of a metropolitan area's housing costs and that Measures A, E, and $\mathrm{F}$ are the worst. However, the evidence from the proxy would be more convincing if the marginal contribution of the housing cost measures to the explanatory power of the model were larger.

Table 5 presents simple linear regressions allowing one to gauge the total contribution each housing cost measure makes toward explaining the variation in the proxy. Table 5 regressions predict the proxy with each available housing cost measure, first in the full sample and then in the ACCRA sample. Results from both samples match those in Table 4: the ranking according to the size of $R$-squared is Measure $\mathrm{D}$, Measure C, and Measure B. Measure D, the average rent per room measure, has an $R$-squared of .25 in the full sample and .27 in the ACCRA sample.

I had expected the housing cost measures to explain more of the variation in average dwelling size among metropolitan areas. The relatively small variation explained could result from the search and moving costs households face. Ihlanfeldt pointed out that a household must usually search and move to change the quantity of housing services it consumes [16]. He suggested that a household will stay in a dwelling until the cost of consuming an undesired quantity of housing exceeds the cost of relocating. If relocation costs influence housing consumption importantly, the quantity of housing consumed by households that moved recently would reflect household preferences better than the quantity consumed by households that have not.
5.2.2. Recent Movers. To test this idea, I reestimated the regressions reported in Tables 3, 4, and 5 on a subgroup of each metropolitan area's households: those that had lived in their current dwelling 5 years or less. ${ }^{17}$ The same housing cost measures are used for the new regressions, but with control variables and the dependent variable recalculated to reflect the characteristics of these "recent movers" and their dwellings. Tables 6,7 , and 8 report the results.

The results suggest that recent movers' dwelling size is indeed more sensitive to metropolitan housing costs than the dwelling size of other households. The marginal contribution of each housing cost measure rises in Table 6 compared to Table 3. Marginal contributions rise or stay the same in Table 7 compared to Table 4 . In addition, total $R$-squared values rise in every case in Table 8 relative to Table 5. Based both on the intuition provided above and on these empirical results, average dwelling size for recent movers seems a better proxy for housing costs than average dwelling size for all households.

How does the performance of the housing cost measures in Tables 6, 7, and 8 compare with that in the earlier tables? It entirely coincides with the results in Tables 4 and 5. In every case Measure D predicts best, Measure C second best, and Measure B third best. Focusing just on Measure D in the large sample, the marginal contribution rises from .057 to .122 and the total contribution ( $R$-squared) rises from .25 to .34 .

The residuals for Measure D regression in Table 4 are relatively well behaved. They are distributed normally and are homoscedastic. They also look extremely linear, with one exception: the effect of income on dwelling size shows sign of declining as the level of a metropolitan area's income rises.

As a robustness check, I present in Table 9 regressions predicting the proxy in a third group of metropolitan areas, those for which the BLS calculates the metropolitan CPI. Table 9 regressions allow me to compare the predictive accuracy of the first through fifth housing cost measures to that of the benchmark measure used in Easton's 2012 article $[1] .^{18}$

The benchmark is the housing cost portion of Aten's area price level index [2]. ${ }^{19}$ It should be a good indicator of housing cost differences among metropolitan areas; she developed it employing the same extensive price data used to calculate the CPI, with help from an economist in the CPI Division of the BLS. $^{20}$

Table 9 provides further evidence that Measure D (the average rent per room measure) is a good measure of housing costs. It predicts 68 percent of the variation in the proxy among the CPI metropolitan areas, while the area price level 
TABLE 2: Variable means and standard deviations*.

\begin{tabular}{|c|c|c|c|}
\hline & Mean & Standard deviation & Metropolitan areas included \\
\hline \multicolumn{4}{|c|}{ Table 1 variables, 1990 to 2000 change } \\
\hline Shelter CPI & 0.334 & 0.0654 & 25 \\
\hline Measure A & 0.300 & 0.0862 & 25 \\
\hline Measure B & 0.344 & 0.1033 & 25 \\
\hline Measure C & 0.379 & 0.1530 & 25 \\
\hline Measure D & 0.423 & 0.0998 & 25 \\
\hline Measure E & 0.287 & 0.0893 & 25 \\
\hline \multicolumn{4}{|c|}{ Table 3 variables, large sample metropolitan areas in 2000, all households } \\
\hline Proxy & 5.508 & 0.438 & 177 \\
\hline Measure A & 1.000 & 0.273 & 177 \\
\hline Measure B & 1.000 & 0.302 & 177 \\
\hline Measure C & 1.000 & 0.385 & 177 \\
\hline Measure D & 1.000 & 0.357 & 177 \\
\hline Measure E & 1.000 & 0.243 & 177 \\
\hline Average household income $(\$ 1,000 \mathrm{~s})$ & 60.317 & 12.255 & 177 \\
\hline Average household size & 2.795 & 0.239 & 177 \\
\hline Proportion of population black & 0.114 & 0.095 & 177 \\
\hline Proportion of population Asian & 0.037 & 0.058 & 177 \\
\hline Proportion of population Hispanic & 0.109 & 0.142 & 177 \\
\hline Proportion of population immigrated in the last 10 years & 0.047 & 0.037 & 177 \\
\hline \multicolumn{4}{|c|}{ Table 4 variables, ACCRA metropolitan areas in 2000, all households } \\
\hline Proxy & 5.528 & 0.409 & 87 \\
\hline Measure A & 0.928 & 0.181 & 87 \\
\hline Measure B & 0.914 & 0.185 & 87 \\
\hline Measure C & 0.974 & 0.200 & 87 \\
\hline Measure D & 0.912 & 0.245 & 87 \\
\hline Measure E & 0.924 & 0.136 & 87 \\
\hline Measure F & 0.991 & 0.200 & 87 \\
\hline Average household income $(\$ 1,000 \mathrm{~s})$ & 56.870 & 6.610 & 87 \\
\hline Average household size & 2.776 & 0.247 & 87 \\
\hline Proportion of population black & 0.119 & 0.093 & 87 \\
\hline Proportion of population Asian & 0.026 & 0.021 & 87 \\
\hline Proportion of population Hispanic & 0.114 & 0.160 & 87 \\
\hline Proportion of population immigrated in the last 10 years & 0.042 & 0.034 & 87 \\
\hline \multicolumn{4}{|c|}{ Table 6 variables, large sample metropolitan areas in 2000, recent movers } \\
\hline Proxy & 5.074 & 0.416 & 177 \\
\hline Average household income ( $\$ 1,000 \mathrm{~s})$ & 54.074 & 10.553 & 177 \\
\hline Average household size & 2.748 & 0.251 & 177 \\
\hline Proportion of population black & 0.126 & 0.098 & 177 \\
\hline Proportion of population Asian & 0.037 & 0.048 & 177 \\
\hline Proportion of population Hispanic & 0.119 & 0.141 & 177 \\
\hline Proportion of population immigrated in the last 10 years & 0.060 & 0.046 & 177 \\
\hline \multicolumn{4}{|c|}{ Table 7 variables, ACCRA metropolitan areas in 2000, recent movers } \\
\hline Proxy & 5.115 & 0.386 & 87 \\
\hline Average household income $(\$ 1,000 \mathrm{~s})$ & 51.416 & 6.334 & 87 \\
\hline Average household size & 2.731 & 0.261 & 87 \\
\hline Proportion of population black & 0.133 & 0.097 & 87 \\
\hline Proportion of population Asian & 0.027 & 0.018 & 87 \\
\hline Proportion of population Hispanic & 0.121 & 0.158 & 87 \\
\hline Proportion of population immigrated in the last 10 years & 0.052 & 0.040 & 87 \\
\hline
\end{tabular}


TABle 2: Continued.

\begin{tabular}{lccc}
\hline & Mean & Standard deviation & Metropolitan areas included \\
\hline & Table 9 variables, & \\
Housing portion of area price level index & 1.022 & 0.242 & 25 \\
Measure A & 1.000 & 0.213 & 25 \\
Measure B & 1.000 & 0.234 & 25 \\
Measure C & 1.000 & 0.307 & 25 \\
Measure D & 1.000 & 0.293 & 25 \\
Measure E & 1.000 & 0.180 & 25 \\
\hline
\end{tabular}

${ }^{*}$ Means and standard deviations for variables are not listed if they have already appeared. For example, those for Table 5 are not listed, since they appear in Tables 3 and 4 .

TABLE 3: Predicting the proxy with controls and Measure A to Measure E, large sample.

\begin{tabular}{|c|c|c|c|c|c|c|}
\hline & Just controls & Measure A & Measure B & Measure C & Measure D & Measure E \\
\hline \multirow{2}{*}{ Constant } & $3.595^{*}$ & $3.753^{*}$ & $3.685^{*}$ & $3.509^{*}$ & $4.008^{*}$ & $3.765^{*}$ \\
\hline & $(0.290)$ & $(0.289)$ & $(0.283)$ & $(0.243)$ & $(0.264)$ & $(0.298)$ \\
\hline \multirow{2}{*}{ Housing cost measure } & & $-0.453^{*}$ & $-0.550^{*}$ & $-0.760^{*}$ & $-0.833^{*}$ & $-0.477^{*}$ \\
\hline & & $(0.154)$ & $(0.162)$ & $(0.088)$ & $(0.120)$ & $(0.190)$ \\
\hline \multirow{2}{*}{ Average household income ( $\$ 1,000$ s) } & $0.013^{*}$ & $0.019^{*}$ & $0.022^{*}$ & $0.026^{*}$ & $0.025^{*}$ & $0.019^{*}$ \\
\hline & $(0.002)$ & $(0.003)$ & $(0.003)$ & $(0.002)$ & $(0.002)$ & $(0.003)$ \\
\hline \multirow{2}{*}{ Average household size } & $0.617^{*}$ & $0.570^{*}$ & $0.563^{*}$ & $0.606^{*}$ & $0.434^{*}$ & $0.575^{*}$ \\
\hline & $(0.106)$ & $(0.105)$ & $(0.104)$ & $(0.088)$ & $(0.097)$ & $(0.107)$ \\
\hline \multirow{2}{*}{ Proportion of population black } & $-0.446^{*}$ & $-0.606^{*}$ & $-0.645^{*}$ & $-0.712^{*}$ & $-0.497^{*}$ & $-0.472^{*}$ \\
\hline & $(0.190)$ & $(0.193)$ & $(0.193)$ & $(0.161)$ & $(0.168)$ & $(0.189)$ \\
\hline \multirow{2}{*}{ Proportion of population Asian } & $-2.835^{*}$ & $-2.379^{*}$ & $-2.158^{*}$ & -0.696 & $-1.367^{*}$ & $-2.512^{*}$ \\
\hline & $(0.363)$ & $(0.387)$ & $(0.404)$ & $(0.391)$ & $(0.385)$ & $(0.379)$ \\
\hline \multirow{2}{*}{ Proportion of population Hispanic } & $-1.601^{*}$ & $-1.586^{*}$ & $-1.499^{*}$ & $-1.550^{*}$ & $-1.325^{*}$ & $-1.569^{*}$ \\
\hline & $(0.243)$ & $(0.238)$ & $(0.238)$ & $(0.203)$ & $(0.219)$ & $(0.241)$ \\
\hline \multirow{2}{*}{ Proportion of population immigrated in the last 10 years } & $-5.764^{*}$ & $-4.883^{*}$ & $-4.903^{*}$ & $-4.629^{*}$ & $-2.562^{*}$ & $-4.844^{*}$ \\
\hline & $(0.869)$ & $(0.901)$ & $(0.880)$ & $(0.737)$ & $(0.897)$ & $(0.935)$ \\
\hline$R$-squared & 0.741 & 0.753 & 0.757 & 0.820 & 0.798 & 0.749 \\
\hline Standard error of estimate & 0.227 & 0.222 & 0.220 & 0.189 & 0.201 & 0.224 \\
\hline Metropolitan areas in sample & 177 & 177 & 177 & 177 & 177 & 177 \\
\hline
\end{tabular}

index finishes second in predictive accuracy and predicts 63 percent.

Having discussed at length the regressions that are part of the second accuracy test, it is time to summarize. What are the lessons to be drawn from the results in Table 3 through Table 9? First, they provide a strong endorsement of Measure D, the measure based on average rent per room. It was the top performer in six of the seven tables. Second, they provide substantial support for Measure C, the hedonic estimator that pools all metropolitan areas. It was the best performer once and the second best five times. Third, they cast serious doubt on the value of Measure F (based on the ACCRA Index). Whether one focuses on marginal or total contributions to explanatory power and whether one focuses on all households or on recent movers, Measure F never places among the top three in predictive accuracy. On the one hand, this is not surprising. C2ER measures housing costs with small, judgment samples; designs their index to measure housing costs in the top quintile of the income distribution; and computes their index using owners' mortgage payments rather than owners' equivalent rent; one would not expect it to be a good measure of the average cost of housing in a metropolitan area. ${ }^{21}$ On the other hand, it is disturbing that the housing portion of the ACCRA Index, a living cost measure frequently used by researchers, measures housing costs so badly.

The poor performance of Measure $\mathrm{F}$ gives credence to Winters [12] and Moretti [13], both of whom rely upon hybrid measures of living costs, combining other measures of housing costs with the nonhousing cost portions of the ACCRA Index. It also underlines the limitations of the many papers that have relied solely on the ACCRA Index as a cost of living measure.

The strong performance of the average rent per room measure, together with its ease of calculation using Census data, suggests it has promise. The variables used to calculate it are available in the American Community Survey (ACS), carried out annually by the Census Bureau since 2005. Substantial sample sizes are available for hundreds of metropolitan areas. $^{22}$ It would be a plausible measure of housing cost 
TABle 4: Predicting the proxy with controls and Measure A to Measure F, ACCRA sample.

\begin{tabular}{|c|c|c|c|c|c|c|c|}
\hline & Just controls & Measure A & Measure B & Measure $\mathrm{C}$ & Measure D & Measure E & Measure F \\
\hline \multirow{2}{*}{ Constant } & $3.204^{*}$ & $3.204^{*}$ & $3.228^{*}$ & $3.363^{*}$ & $3.301^{*}$ & $3.202^{*}$ & $3.202^{*}$ \\
\hline & $(0.414)$ & $(0.417)$ & $(0.414)$ & $(0.415)$ & $(0.380)$ & $(0.422)$ & $(0.420)$ \\
\hline \multirow{2}{*}{ Housing cost measure } & & -0.004 & -0.269 & -0.377 & $-0.879^{*}$ & 0.008 & 0.004 \\
\hline & & $(0.233)$ & $(0.238)$ & $(0.190)$ & $(0.216)$ & $(0.369)$ & $(0.162)$ \\
\hline \multirow{2}{*}{$\begin{array}{l}\text { Average household income } \\
(\$ 1,000 \mathrm{~s})\end{array}$} & $0.024^{*}$ & $0.024^{*}$ & $0.029^{*}$ & $0.027^{*}$ & $0.040^{*}$ & $0.024^{*}$ & $0.024^{*}$ \\
\hline & $(0.004)$ & $(0.006)$ & $(0.006)$ & $(0.004)$ & $(0.005)$ & $(0.007)$ & $(0.004)$ \\
\hline \multirow{2}{*}{ Average household size } & $0.553^{*}$ & $0.553^{*}$ & $0.524^{*}$ & $0.544^{*}$ & $0.400^{*}$ & $0.554^{*}$ & $0.553^{*}$ \\
\hline & $(0.121)$ & $(0.124)$ & $(0.124)$ & $(0.119)$ & $(0.117)$ & $(0.124)$ & $(0.122)$ \\
\hline \multirow{2}{*}{ Proportion of population black } & -0.299 & -0.300 & -0.372 & -0.333 & -0.227 & -0.299 & -0.298 \\
\hline & $(0.237)$ & $(0.245)$ & $(0.246)$ & $(0.234)$ & $(0.218)$ & $(0.239)$ & $(0.239)$ \\
\hline \multirow{2}{*}{ Proportion of population Asian } & $-7.252^{*}$ & $-7.244^{*}$ & $-6.446^{*}$ & $-5.273^{*}$ & $-4.042^{*}$ & $-7.262^{*}$ & $-7.278^{*}$ \\
\hline & $(1.291)$ & $(1.397)$ & $(1.473)$ & $(1.613)$ & $(1.420)$ & $(1.395)$ & $(1.684)$ \\
\hline \multirow{2}{*}{$\begin{array}{l}\text { Proportion of population } \\
\text { Hispanic }\end{array}$} & $-1.156^{*}$ & $-1.155^{*}$ & $-1.069^{*}$ & $-1.187^{*}$ & $-0.774^{*}$ & $-1.157^{*}$ & $-1.156^{*}$ \\
\hline & $(0.269)$ & $(0.273)$ & $(0.280)$ & $(0.265)$ & $(0.264)$ & $(0.279)$ & $(0.271)$ \\
\hline \multirow{2}{*}{$\begin{array}{l}\text { Proportion of population } \\
\text { immigrated in the last } 10 \text { years }\end{array}$} & $-5.413^{*}$ & $-5.410^{*}$ & $-5.352^{*}$ & $-5.115^{*}$ & $-3.082^{*}$ & $-5.420^{*}$ & $-5.410^{*}$ \\
\hline & $(1.188)$ & $(1.214)$ & $(1.187)$ & $(1.176)$ & $(1.228)$ & $(1.246)$ & $(1.204)$ \\
\hline$R$-squared & 0.789 & 0.789 & 0.792 & 0.799 & 0.825 & 0.789 & 0.789 \\
\hline Standard error of estimate & 0.195 & 0.196 & 0.195 & 0.191 & 0.178 & 0.196 & 0.196 \\
\hline Metropolitan areas in sample & 87 & 87 & 87 & 87 & 87 & 87 & 87 \\
\hline
\end{tabular}

TABle 5: Predicting the proxy with housing cost measures alone.

\begin{tabular}{|c|c|c|c|c|c|c|}
\hline & Measure A & Measure B & Measure C & Measure D & Measure E & Measure F \\
\hline \multicolumn{7}{|l|}{ Large sample } \\
\hline \multirow{2}{*}{ Constant } & $5.959^{*}$ & $5.927^{*}$ & $5.967^{*}$ & $6.124^{*}$ & $6.018^{*}$ & \\
\hline & $(0.121)$ & $(0.110)$ & $(0.084)$ & $(0.085)$ & $(0.136)$ & \\
\hline \multirow{2}{*}{ Housing cost measure } & $-0.451^{*}$ & $-0.419^{*}$ & $-0.459^{*}$ & $-0.616^{*}$ & $-0.517^{*}$ & \\
\hline & $(0.116)$ & $(0.105)$ & $(0.079)$ & $(0.080)$ & $(0.132)$ & \\
\hline$R$-squared & 0.079 & 0.083 & 0.163 & 0.252 & 0.082 & \\
\hline SEE & 0.421 & 0.420 & 0.402 & 0.380 & 0.421 & \\
\hline Metropolitan areas & 176 & 176 & 176 & 176 & 176 & \\
\hline \multicolumn{7}{|l|}{ ACCRA sample } \\
\hline \multirow{2}{*}{ Constant } & $5.852^{*}$ & $6.034^{*}$ & $6.252^{*}$ & $6.324^{*}$ & $6.211^{*}$ & $5.983^{*}$ \\
\hline & $(0.229)$ & $(0.217)$ & $(0.206)$ & $(0.146)$ & $(0.295)$ & $(0.218)$ \\
\hline \multirow{2}{*}{ Housing cost measure } & -0.348 & $-0.553^{*}$ & $-0.825^{*}$ & $-0.872^{*}$ & $-0.739^{*}$ & $-0.005^{*}$ \\
\hline & $(0.242)$ & $(0.233)$ & $(0.230)$ & $(0.155)$ & $(0.316)$ & $(0.002)$ \\
\hline$R$-squared & 0.024 & 0.062 & 0.132 & 0.272 & 0.061 & 0.050 \\
\hline SEE & 0.406 & 0.398 & 0.383 & 0.351 & 0.399 & 0.401 \\
\hline Metropolitan areas & 87 & 87 & 87 & 87 & 87 & 87 \\
\hline
\end{tabular}

differences among those metropolitan areas. It would also be a plausible measure of housing costs for a Winters-style cost of living measure, calculated for the ACCRA metropolitan areas.

\section{Conclusions}

In this research, I evaluate six alternative measures of metropolitan housing costs, to contribute to the development of a living cost measure that would allow researchers to accurately compare real earnings among US metropolitan areas. The research tests the housing cost measures in two ways. First, it tests their ability to predict the 1990-to2000 change in the shelter portion of the CPI among 25 large metropolitan areas. Second, it tests their ability to predict a proxy for housing costs in much larger groups of metropolitan areas in 2000. The proxy is the average size of the dwellings occupied by a metropolitan area's residents.

The results of the two evaluations are similar, but not identical. In the first test, the measure based on average rent 
TABLE 6: Predicting the proxy with controls and housing cost Measure A to Measure E, recent movers in large sample.

\begin{tabular}{|c|c|c|c|c|c|c|}
\hline & Just controls & Measure A & Measure B & Measure C & Measure D & Measure E \\
\hline \multirow{2}{*}{ Constant } & $3.800^{*}$ & $3.910^{*}$ & $3.806^{*}$ & $3.544^{*}$ & $4.003^{*}$ & $4.017^{*}$ \\
\hline & $(0.296)$ & $(0.275)$ & $(0.274)$ & $(0.235)$ & $(0.210)$ & $(0.284)$ \\
\hline \multirow{2}{*}{ Housing cost measure } & & $-0.783^{*}$ & $-0.796^{*}$ & $-0.812^{*}$ & $-1.118^{*}$ & $-0.804^{*}$ \\
\hline & & $(0.144)$ & $(0.145)$ & $(0.080)$ & $(0.085)$ & $(0.179)$ \\
\hline \multirow{2}{*}{ Average household income ( $\$ 1,000 \mathrm{~s})$} & $0.011^{*}$ & $0.024^{*}$ & $0.026^{*}$ & $0.027^{*}$ & $0.031^{*}$ & $0.023^{*}$ \\
\hline & $(0.002)$ & $(0.003)$ & $(0.003)$ & $(0.002)$ & $(0.002)$ & $(0.003)$ \\
\hline \multirow{2}{*}{ Average household size } & $0.447^{*}$ & $0.410^{*}$ & $0.410^{*}$ & $0.495^{*}$ & $0.294^{*}$ & $0.393^{*}$ \\
\hline & $(0.109)$ & $(0.101)$ & $(0.101)$ & $(0.086)$ & $(0.078)$ & $(0.104)$ \\
\hline \multirow{2}{*}{ Proportion of population black } & -0.316 & $-0.638^{*}$ & $-0.649^{*}$ & $-0.696^{*}$ & $-0.504^{*}$ & $-0.395^{*}$ \\
\hline & $(0.197)$ & $(0.192)$ & $(0.192)$ & $(0.160)$ & $(0.140)$ & $(0.189)$ \\
\hline \multirow{2}{*}{ Proportion of population Asian } & $-4.288^{*}$ & $-3.136^{*}$ & $-2.842^{*}$ & $-1.253^{*}$ & $-1.368^{*}$ & $-3.448^{*}$ \\
\hline & $(0.493)$ & $(0.503)$ & $(0.525)$ & $(0.489)$ & $(0.413)$ & $(0.498)$ \\
\hline \multirow{2}{*}{ Proportion of population Hispanic } & $-1.833^{*}$ & $-1.725^{*}$ & $-1.633^{*}$ & $-1.706^{*}$ & $-1.215^{*}$ & $-1.703^{*}$ \\
\hline & $(0.257)$ & $(0.239)$ & $(0.241)$ & $(0.204)$ & $(0.188)$ & $(0.245)$ \\
\hline \multirow{2}{*}{ Proportion of population immigrated in the last 10 years } & $-2.200^{*}$ & $-1.723^{*}$ & $-1.803^{*}$ & $-2.178^{*}$ & -0.690 & $-1.401^{*}$ \\
\hline & $(0.716)$ & $(0.669)$ & $(0.665)$ & $(0.565)$ & $(0.518)$ & $(0.701)$ \\
\hline$R$-squared & 0.679 & 0.727 & 0.728 & 0.801 & 0.841 & 0.720 \\
\hline Standard error of estimate & 0.240 & 0.222 & 0.222 & 0.189 & 0.169 & 0.226 \\
\hline Metropolitan areas in sample & 177 & 177 & 177 & 177 & 177 & 177 \\
\hline
\end{tabular}

TABLE 7: Predicting the proxy with controls and housing cost Measure A to Measure F, recent movers in ACCRA sample.

\begin{tabular}{|c|c|c|c|c|c|c|c|}
\hline & Just controls & Measure A & Measure B & Measure C & Measure D & Measure E & Measure F \\
\hline \multirow{2}{*}{ Constant } & $3.599^{*}$ & $3.607^{*}$ & $3.707^{*}$ & $3.759^{*}$ & $3.645^{*}$ & $3.638^{*}$ & $3.611^{*}$ \\
\hline & $(0.384)$ & $(0.388)$ & $(0.383)$ & $(0.365)$ & $(0.310)$ & $(0.394)$ & $(0.403)$ \\
\hline \multirow{2}{*}{ Housing cost measure } & & -0.045 & -0.387 & $-0.544^{*}$ & $-1.054^{*}$ & -0.169 & -0.017 \\
\hline & & $(0.217)$ & $(0.214)$ & $(0.164)$ & $(0.159)$ & $(0.357)$ & $(0.160)$ \\
\hline \multirow{2}{*}{$\begin{array}{l}\text { Average household income } \\
(\$ 1,000 \mathrm{~s})\end{array}$} & $0.018^{*}$ & $0.019^{*}$ & $0.024^{*}$ & $0.022^{*}$ & $0.038^{*}$ & $0.020^{*}$ & $0.018^{*}$ \\
\hline & $(0.004)$ & $(0.006)$ & $(0.005)$ & $(0.004)$ & $(0.005)$ & $(0.006)$ & $(0.004)$ \\
\hline \multirow{2}{*}{ Average household size } & $0.427^{*}$ & $0.423^{*}$ & $0.380^{*}$ & $0.437^{*}$ & $0.278^{*}$ & $0.419^{*}$ & $0.426^{*}$ \\
\hline & $(0.117)$ & $(0.118)$ & $(0.118)$ & $(0.110)$ & $(0.097)$ & $(0.118)$ & $(0.117)$ \\
\hline \multirow{2}{*}{ Proportion of population black } & -0.257 & -0.271 & -0.397 & -0.334 & -0.315 & -0.274 & -0.259 \\
\hline & $(0.231)$ & $(0.242)$ & $(0.240)$ & $(0.219)$ & $(0.187)$ & $(0.235)$ & $(0.233)$ \\
\hline \multirow{2}{*}{ Proportion of population Asian } & $-9.215^{*}$ & $-9.082^{*}$ & $-7.720^{*}$ & $-6.166^{*}$ & $-3.923^{*}$ & $-8.840^{*}$ & $-9.076^{*}$ \\
\hline & $(1.415)$ & $(1.559)$ & $(1.622)$ & $(1.621)$ & $(1.396)$ & $(1.629)$ & $(1.929)$ \\
\hline \multirow{2}{*}{$\begin{array}{l}\text { Proportion of population } \\
\text { Hispanic }\end{array}$} & $-1.550^{*}$ & $-1.546^{*}$ & $-1.438^{*}$ & $-1.567^{*}$ & $-0.982^{*}$ & $-1.520^{*}$ & $-1.550^{*}$ \\
\hline & $(0.254)$ & $(0.256)$ & $(0.258)$ & $(0.240)$ & $(0.223)$ & $(0.263)$ & $(0.256)$ \\
\hline \multirow{2}{*}{$\begin{array}{l}\text { Proportion of population } \\
\text { immigrated in the last } 10 \text { years }\end{array}$} & $-2.054^{*}$ & $-2.017^{*}$ & $-1.968^{*}$ & $-1.909^{*}$ & -0.618 & $-1.944^{*}$ & $-2.061^{*}$ \\
\hline & $(0.824)$ & $(0.847)$ & $(0.814)$ & $(0.778)$ & $(0.700)$ & $(0.860)$ & $(0.832)$ \\
\hline$R$-squared & 0.764 & 0.764 & 0.773 & 0.793 & 0.848 & 0.764 & 0.764 \\
\hline Standard error of estimate & 0.195 & 0.196 & 0.192 & 0.184 & 0.157 & 0.196 & 0.196 \\
\hline Metropolitan areas in sample & 87 & 87 & 87 & 87 & 87 & 87 & 87 \\
\hline
\end{tabular}

per room predicts best, by a wide margin. It predicts $69 \%$ of the variation in changes in the shelter CPI from 1990 to 2000. The measure constructed from Fair Market Rents calculated by HUD predicts shelter CPI changes second best, with an $R$-squared 18 points lower. A measure calculated with a hedonic indicator of housing costs in tenant- and owner-occupied housing, estimated in a pooled sample of metropolitan areas, predicts third best. In the second test, performance varies somewhat among the versions of the test performed. However, the average rent per room measure almost always predicts the proxy best, the pooled hedonic indicator generally places second, and another hedonic indicator generally places third. The Fair Market Rents measure never places higher than fourth. 
TABLE 8: Predicting the proxy with housing cost measures alone, recent movers.

\begin{tabular}{|c|c|c|c|c|c|c|}
\hline & Measure A & Measure B & Measure C & Measure D & Measure E & Measure F \\
\hline \multicolumn{7}{|l|}{ Large sample } \\
\hline \multirow{2}{*}{ Constant } & $5.624^{*}$ & $5.598^{*}$ & $5.601^{*}$ & $5.753^{*}$ & $5.711^{*}$ & \\
\hline & $(0.111)$ & $(0.101)$ & $(0.077)$ & $(0.076)$ & $(0.125)$ & \\
\hline \multirow{2}{*}{ Housing cost measure } & $-0.550^{*}$ & $-0.524^{*}$ & $-0.527^{*}$ & $-0.679^{*}$ & $-0.642^{*}$ & \\
\hline & $(0.107)$ & $(0.096)$ & $(0.071)$ & $(0.072)$ & $(0.122)$ & \\
\hline$R$-squared & 0.130 & 0.144 & 0.237 & 0.340 & 0.139 & \\
\hline SEE & 0.389 & 0.386 & 0.365 & 0.339 & 0.389 & \\
\hline Metropolitan areas & 177 & 177 & 177 & 177 & 177 & \\
\hline \multicolumn{7}{|l|}{ ACCRA sample } \\
\hline \multirow{2}{*}{ Constant } & $5.493^{*}$ & $5.702^{*}$ & $5.857^{*}$ & $5.929^{*}$ & $5.874^{*}$ & $5.666^{*}$ \\
\hline & $(0.215)$ & $(0.201)$ & $(0.192)$ & $(0.133)$ & $(0.275)$ & $(0.203)$ \\
\hline \multirow{2}{*}{ Housing cost measure } & -0.408 & $-0.643^{*}$ & $-0.845^{*}$ & $-0.893^{*}$ & $-0.822^{*}$ & $-0.556^{*}$ \\
\hline & $(0.227)$ & $(0.216)$ & $(0.214)$ & $(0.141)$ & $(0.295)$ & $(0.201)$ \\
\hline$R$-squared & 0.036 & 0.094 & 0.155 & 0.320 & 0.084 & 0.083 \\
\hline SEE & 0.381 & 0.370 & 0.357 & 0.321 & 0.372 & 0.372 \\
\hline Metropolitan areas & 87 & 87 & 87 & 87 & 87 & 87 \\
\hline
\end{tabular}

TABLE 9: Predicting the proxy with housing cost measures alone, recent movers in BLS metropolitan areas.

\begin{tabular}{|c|c|c|c|c|c|c|}
\hline & Area price level & Measure A & Measure B & Measure C & Measure D & Measure E \\
\hline \multirow{2}{*}{ Constant } & $6.540^{*}$ & $6.472^{*}$ & $6.465^{*}$ & $6.036^{*}$ & $6.283^{*}$ & $6.639^{*}$ \\
\hline & $(0.263)$ & $(0.352)$ & $(0.293)$ & $(0.241)$ & $(0.201)$ & $(0.436)$ \\
\hline \multirow{2}{*}{ Housing cost measure } & $-1.583^{*}$ & $-1.550^{*}$ & $-1.543^{*}$ & $-1.114^{*}$ & $-1.361^{*}$ & $-1.717^{*}$ \\
\hline & $(0.251)$ & $(0.345)$ & $(0.285)$ & $(0.231)$ & $(0.193)$ & $(0.429)$ \\
\hline$R$-squared & 0.633 & 0.468 & 0.560 & 0.503 & 0.684 & 0.410 \\
\hline Standard error of estimate & 0.298 & 0.359 & 0.327 & 0.347 & 0.277 & 0.378 \\
\hline Metropolitan areas in sample & 25 & 25 & 25 & 25 & 25 & 25 \\
\hline
\end{tabular}

Easton assessed the same six housing cost measures [1], testing their ability to predict variation in Aten's area price level index, an index calculated from the extensive price data used to create the CPI [2]. He concluded that the rent per room measure was the best gauge of housing costs, the measure based on Fair Market Rents was second best, and the measure based on the housing portion of the ACCRA Index was third best.

This research strongly endorses Easton's conclusion about the rent per room measure. Given its consistent predictive success, it is a plausible measure of housing cost differences among US metropolitan areas. Moreover, it is one that can be easily calculated for hundreds of metropolitan areas using American Community Survey data. However, this research finds much weaker support for the housing portion of the ACCRA Index; across four different versions of the second test, it never places among the top three measures in predictive accuracy. Its verdict regarding the Fair Market Rents measure is mixed, since it performed well on the first test, but badly on the second.

What guidance does this research offer scholars needing a measure of living costs across a large number of US metropolitan areas? It suggests a combined approach. Though the ACCRA housing cost measure predicts badly and has substitutes, the ACCRA measure of nonhousing costs is better constructed and is unique. As a result, it seems promising to create a living cost measure that combines the rent per room measure of housing cost tested here with the nonhousing cost portion of the ACCRA Index. ${ }^{23}$ Winters' index offers a good model for how this combination might be carried out [12]. His index is a weighted average of a rentbased housing cost measure he calculates and the nonhousing cost portion of the ACCRA Index.

A possible improvement on this strategy would be to adopt a hybrid approach, using a Winters-style measure for smaller metropolitan areas and area price level measures for the 27 large, aggregated metropolitan areas for which CPI price data are available [2,17]. Area price level indexes for these areas are available only for 2003, 2004, 2005, and 2006, but they can be brought forward or backward using metropolitan CPI data.

For a researcher needing living cost measures only for a limited number of recent years, another resource is available. Research sponsored by the Bureau of Economic Analysis just released experimental measures of living costs for 366 metropolitan statistical areas in 2009, 2010, and 2011 [18]. These "regional price parity" measures combine estimates of rents from each metropolitan statistical area made using 
ACS data with estimates of nonhousing prices from the much larger areas over which CPI price data are aggregated.

\section{Conflict of Interests}

The author declares that there is no conflict of interests regarding the publication of this paper.

\section{Endnotes}

1. The last official measure was the Bureau of Labor Statistics' comparative cost index, reported in the Monthly Labor Review. The last data published included living cost measures for 25 metropolitan areas in 1981 [19]. For living costs in 1979 and prior years, the data included 40 metropolitan areas.

2. Throughout the paper, I seek to measure tenant's rent and owner's equivalent rent, that is, housing costs excluding utilities.

3. For example, suppose one predicts the change in the metropolitan CPI with the change in the metropolitan shelter CPI. Using the change from 1989 to 1999 , in the 25 metropolitan areas the BLS reports data for, the $R$ squared is .60 .

4. Dumond et al. create their index by projecting the comparative cost index from 1981 to 1989 using the CPI$\mathrm{U}$, working with the 22 metropolitan areas for which the CPI-U was available [11].

5. Winters argues that his measure of housing costs should be more accurate than the ACCRA measure, since it estimates solely metropolitan rents, while the ACCRA measure heavily weights homeowners' principal and interest payments. Of the housing cost measures tested in this paper, this rent-based index is closest to Measure A.

6. Easton's paper has a more detailed presentation [1].

7. The biggest difference is that my approach uses the rent of a metropolitan area's average tenant-occupied dwelling to also represent the owner's equivalent rent of the average owner-occupied dwelling. The CPI uses the rent of the average tenant-occupied dwelling in a similar way, but within a neighborhood rather than within an entire metropolitan area.

8. Every dwelling attribute available in the Census is included in vector $X$; there are nineteen elements in the vector. Details on the estimation of this and the subsequent two relationships are in Easton [1].

9. The characteristics of the average dwelling were determined by pooling all the rented dwellings in the 1990 and 2000 samples. Rent was predicted for a four-room dwelling in a thirty-year-old, seven-unit building.

10. To be more specific about DwCost: if the dwelling is rented, the rent value used is the census gross rent less reported payments for utilities. If the dwelling is owneroccupied, the house value used is the census house value, which is an estimate provided to the enumerator by the respondent.

11. Though the approach is the same, the characteristics utilized were those of the average owner-occupied dwelling. Rent was estimated for a detached, six-room, thirtyyear-old house.

12. HUD used the 40th percentile standard as described from 1995 to 2000. Before 1995 FMRs estimated the 45th percentile. Beginning in 2001, HUD estimated the 40th percentile in most metropolitan areas but estimated the 50th in areas where voucher recipients had trouble renting apartments in a broad range of neighborhoods [20].

13. Dean Frutiger (Project Manager for C2ER's Cost of Living Index) confirmed this mode of calculation for the housing component in a 12/4/12 e-mail. In addition, on the "Review of the Cost of Living Index Methodology" page, the Council for Community and Economic Research says weights are "based on data from the U.S. Bureau of Labor Statistics' 2004 Consumer Expenditure Survey, using the data on the proportional distribution of expenditures by households in which the reference person has a professional or managerial occupation and by households in the upper quintile of income" [21].

14. Fair Market Rents can be downloaded from http://www .huduser.org/portal/datasets/fmr.html; the page title is "Fair Market Rents | HUD USER."

15. The change in housing costs is calculated in log points in each case. For Measure A and Measure B, it is calculated with a Laspeyres Index (i.e., as the change in value of the 1990 housing stock, going from 1990 attribute rents to 2000 attribute rents). For Measure C, it is the change in the cost of the "average dwelling" in the 1990 sample (detached, five rooms, thirty years old). For Measure D, it is the change in the average rent per room. For Measure $\mathrm{E}$, it is the change in the two-bedroom FMR.

16. The shelter portion of the CPI includes the "rent of primary residence" and "owners' equivalent rent of primary residence." Together, they averaged $90.5 \%$ of the shelter index in the metropolitan CPI-U. The remainder of the shelter index is made up of lodging away from home and tenants' and household insurance [22].

17. I also reestimated some of Table 3 regressions on households that had lived in their dwelling 2 or fewer years. $R$ squared values were slightly lower than those reported in Table 3, perhaps due to reductions in metropolitan sample sizes. The average metropolitan sample was 3,876 households/dwellings in Table 3 regressions. It was 56\% of that when estimated with households that had lived in their dwelling 5 or fewer years and only $23 \%$ of that when estimated with households that had lived in their dwelling 2 or fewer years.

18. I present only simple linear regressions for these regressions. Estimates of (5) had serious multicollinearity in this small sample. Measure F, the ACCRA Index, is 
omitted from Table 9 because it is available for only 16 of these 25 metropolitan areas.

19. Aten calculated her index for 2003. Easton projected it backwards to 2000 using rates of shelter cost inflation published by the BLS [1].

20. The BLS collects a large, sophisticated sample of dwellings. Small groups of census blocks (referred to as "neighborhoods" in Note 7) are selected at random to represent each metropolitan area, with almost 10,000 such groups used for the CPI. Rents are collected for about 27,000 tenant-occupied dwellings across the whole sample. The dwellings are priced twice a year. Rents are assigned to about 30,000 owner-occupied dwellings across the whole sample, based on rents in the tenantoccupied dwellings in the same group of census blocks $[2,23]$. Though the benchmark should be an excellent measure of housing costs, it would be an even better indicator if it measured shelter costs rather than housing costs; CPI housing cost data include rent and owners' equivalent rent (which together comprise most of CPI shelter costs), but they also include fuels, utilities, and household furnishings. The shelter index's weight in the housing index averaged $77.7 \%$ in the 2000 metropolitan CPI-U [22]. The remaining portion includes fuels and utilities (10.9\%) and household furnishings and operations $(11.4 \%)$.

21. The ACCRA Index manual specifies that at least five houses must be priced in each urban metropolitan area [24]. The survey form has 15 spaces to report house prices [25]. The manual has no mention of random sampling and describes the sorts of judgments volunteers collecting prices should make. Here is one example: "Your selection of samples for all items in the Index should be guided by what's typical for professional and managerial households in the top income quintile" ([24], p. 12).

22. The 2005-2007 ACS identifies 297 metropolitan areas; the smallest metropolitan sample includes 2,535 households.

23. Though it is calculated using a small set of prices, those prices are collected for a large set of metropolitan areas.

\section{References}

[1] T. Easton, "Optimal housing cost estimates for 177 U.S. metropolitan areas," Journal of Regional Science, vol. 52, no. 3, pp. 469485, 2012.

[2] B. H. Aten, "Interarea price levels: an experimental methodology," Monthly Labor Review, vol. 129, no. 9, pp. 47-58, 2006.

[3] J. Koo, K. R. Phillips, and F. D. Sigalla, "Measuring regional cost of living," Journal of Business and Economic Statistics, vol. 18, no. 1, pp. 127-136, 2000.

[4] L. B. Curran, H. Wolman, E. W. Hill, and K. Furdell, "Economic wellbeing and where we live: accounting for geographical costof-living differences in the US," Urban Studies, vol. 43, no. 13, pp. 2443-2466, 2006.
[5] M. Browne and J. Trieschmann, "Salary and benefit compensation at American Research Universities," Journal of Risk and Insurance, vol. 58, no. 3, pp. 513-524, 1991.

[6] D. M. Cutler and E. L. Glaeser, "Are ghettos good or bad?" Quarterly Journal of Economics, vol. 112, no. 3, pp. 826-872, 1997.

[7] M. Gisser and A. Dávila, "Do farm workers earn less? An analysis of the farm labor problem," The American Journal of Agricultural Economics, vol. 80, no. 4, pp. 669-682, 1998.

[8] C. A. Olson, D. P. Schwab, and B. L. Rau, "The effects of local market conditions on two pay-setting systems in the federal sector," Industrial and Labor Relations Review, vol. 53, no. 2, pp. 272-289, 2000.

[9] T. Easton, “Immigration and natives' wages: understanding their correlation in the 1980s," The Review of Regional Studies, vol. 31, no. 3, pp. 219-235, 2001.

[10] E. L. Glaeser and K. Tobio, “The rise of the sunbelt," Southern Economic Journal, vol. 74, no. 3, pp. 609-643, 2008.

[11] J. M. Dumond, B. Hirsch, and D. Macpherson, "Wage differentials across labor markets and workers: does cost of living matter?" Economic Inquiry, vol. 37, no. 4, pp. 577-598, 1999.

[12] J. V. Winters, "Wages and prices: are workers fully compensated for cost of living differences?" Regional Science and Urban Economics, vol. 39, no. 5, pp. 632-643, 2009.

[13] E. Moretti, "Real wage inequality," American Economic Journal: Applied Economics, vol. 5, no. 1, pp. 65-103, 2013.

[14] T. M. Crone, L. I. Nakamura, and R. Voith, "Hedonic estimates of the cost of housing services: rental and owner-occupied units,' Working Paper 04-22, Federal Reserve Bank of Philadelphia, 2004.

[15] S. Ruggles, J. T. Alexander, K. Genadek, R. Goeken, M. B. Schroeder, and M. Sobek, Integrated Public Use Microdata Series: Version 5.0 [Machine-Readable Database], University of Minnesota, Minneapolis, Minn, USA, 2010.

[16] K. R. Ihlanfeldt, "An empirical investigation of alternative approaches to estimating the equilibrium demand for housing," Journal of Urban Economics, vol. 9, no. 1, pp. 97-105, 1981.

[17] B. H. Aten and R. D'Souza, "Research spotlight: regional price parities, comparing price level differences across geographic areas," Survey of Current Business, pp. 64-74, 2008.

[18] B. Aten, E. Figueroa, and T. Martin, "Real personal income and Regional Price Parities for States and Metropolitan Areas, 20072011," Survey of Current Business, pp. 89-103, 2013.

[19] "Final report on family budgets: cost increases slowed, Autumn 1981," Monthly Labor Review, vol. 105, no. 7, pp. 44-46, 1982.

[20] Department of Housing and Urban Development (HUD), "HUD Archives: Description of HUD's New Policy on Fair Market Rents," 2001, http://archives.hud.gov/news/2000/pr00223attachtech.html.

[21] Council for Community and Economic Research (C2ER), Review of the Cost of Living Index Methodology, Council for Community and Economic Research, Arlington, Va, USA, 2012, http://www.coli.org/Method.asp.

[22] Department of Labor and Bureau of Labor Statistics, "Table 1 (1999-2000 Weights). Relative importance of components in the Consumer Price Indexes: U.S. city average," 2002, http:// www.bls.gov/cpi/relimp_2002.pdf.

[23] Department of Labor; Bureau of Labor Statistics, "Chapter 17: the consumer price index," in BLS Handbook of Methods, 2008, http://www.bls.gov/opub/hom/pdf/homch17.pdf. 
[24] Council for Community and Economic Research (C2ER), ACCRA Cost of Living Index Manual, Arlington, Va, USA, 2008, http://www.coli.org/surveyforms/colimanual.pdf.

[25] Council for Community and Economic Research (C2ER), "Cost of Living Index Price Report," 2012, http://www.coli.org/ surveyforms/pricesurvey.pdf. 

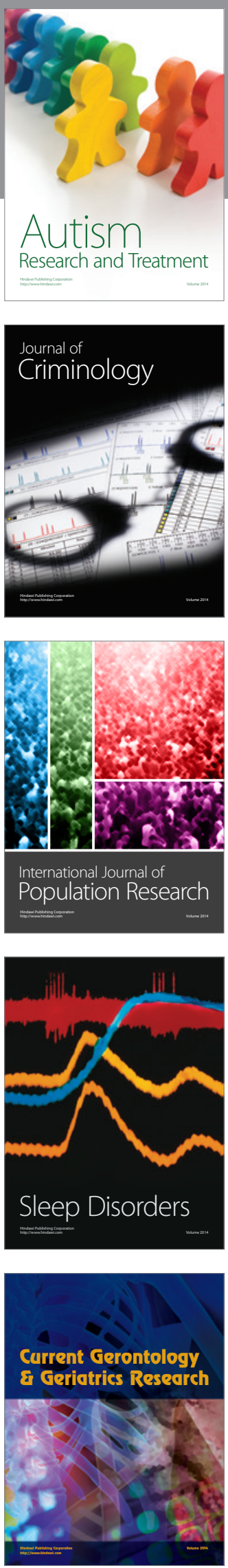
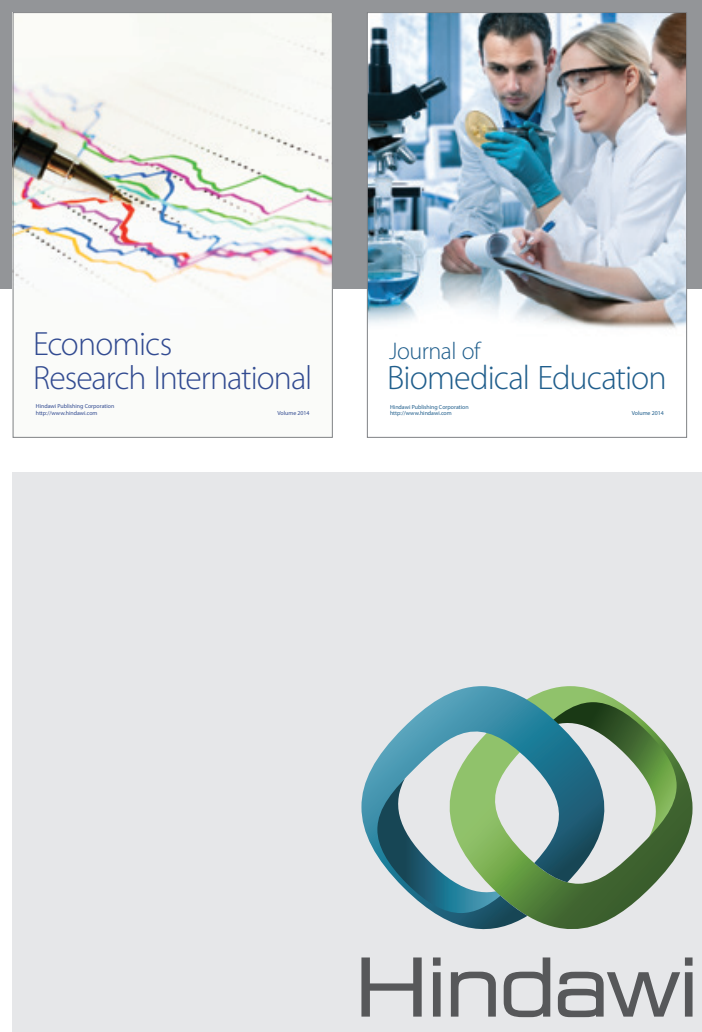

Submit your manuscripts at

http://www.hindawi.com
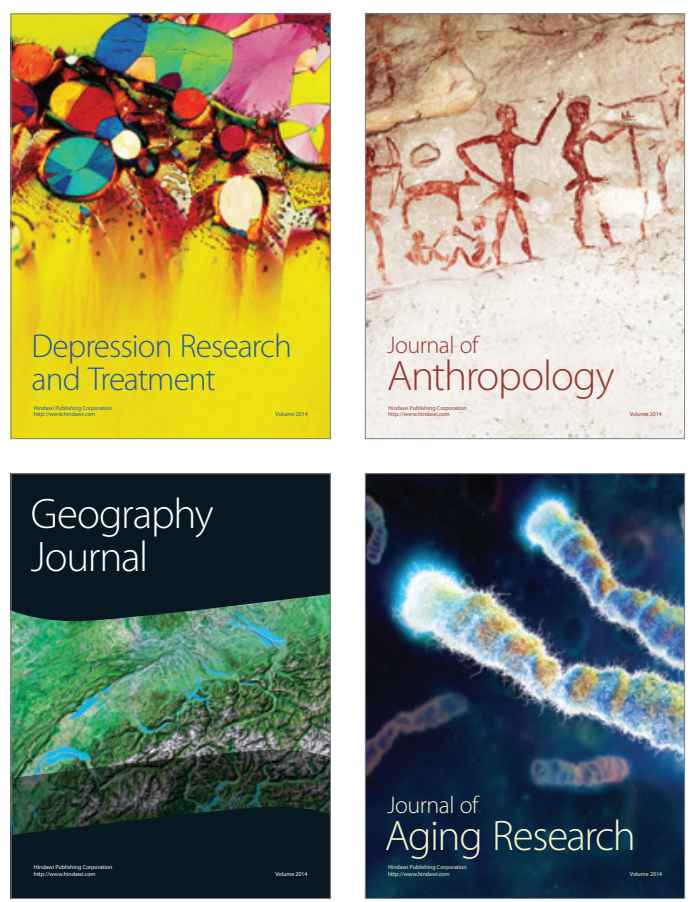
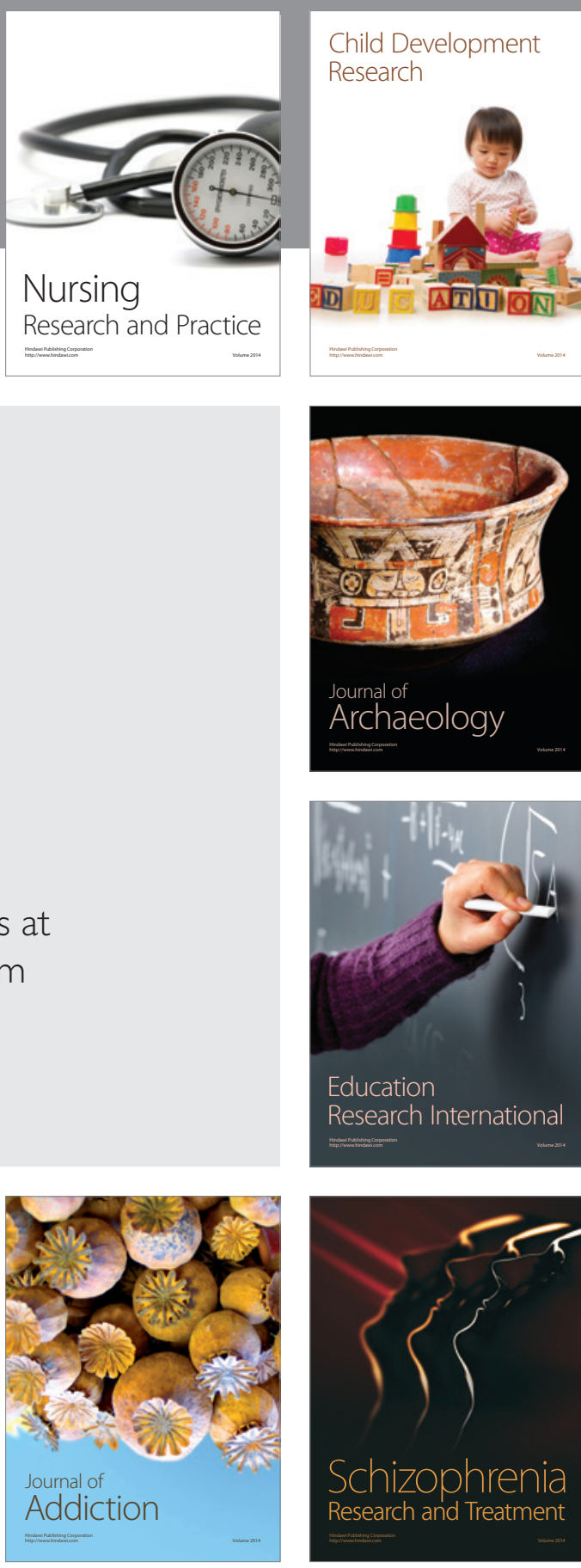

(D)
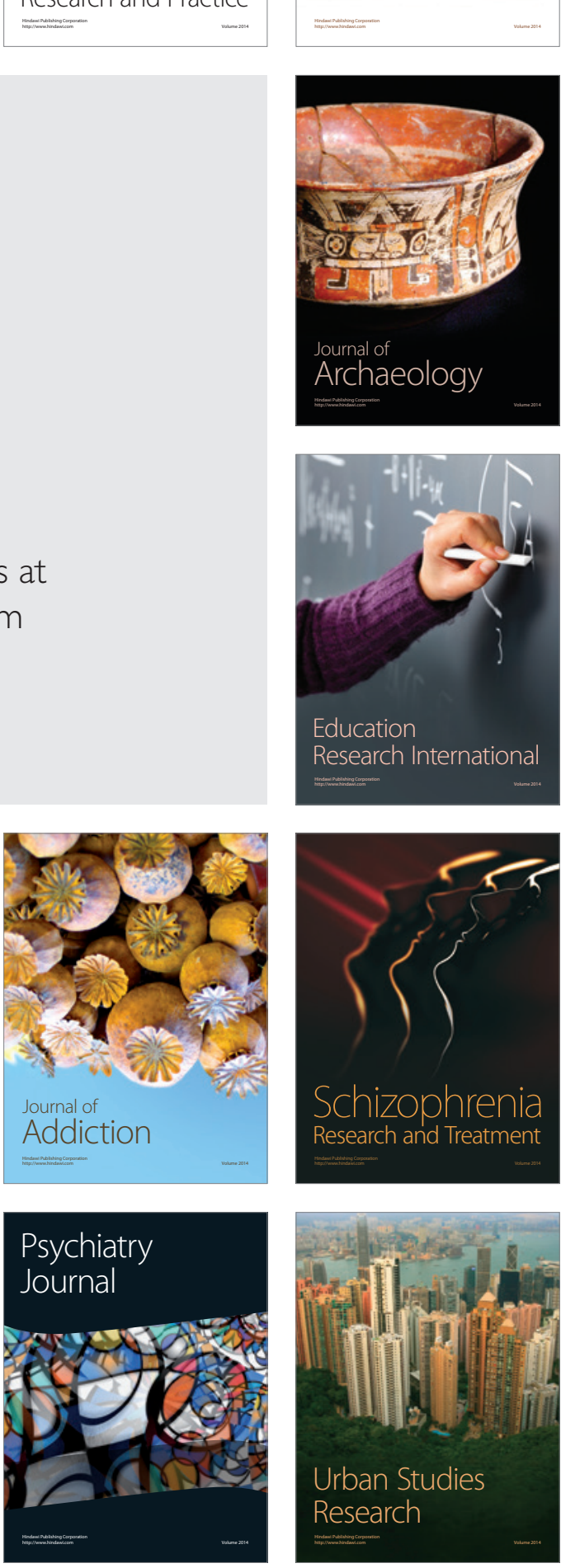